\title{
Triple Helix and Innovation in the life-science industry
}

\author{
Chiara D'Alise, Luca Giustiniano, LUISS Guido Carli University
}

\begin{abstract}
The paper analyses the impact of the "Triple Helix" on innovation by assuming a network theory approach. The aim is to build a theoretical framework to improve the understanding of the effect of clusters involving industrial, academic and institutional players on the cluster's innovation. In particular the work is focused on intra-cluster and inter-cluster structural and nodal characteristics in the life-science industry.
\end{abstract}

Keywords: innovation; knowledge; cluster; network; lifescience; triple helix.

\section{INTRODUCTION}

Strong links between the production structure and the knowledge and institutional infrastructure in science-based industries are necessary to overcome innovation challenges: innovations could result directly from ongoing interactions among scientific, commercial, educational, and public institutions, in a context of bridging between different worldviews.

The "Triple Helix" (TH) Model of knowledge, developed by references [1];[2] will be theoretically investigated in this paper by assuming a Network approach. The model is focused on three helices that intertwine in university-industrygovernment relations and networks. These helices overlap and create synergies that result in product and process innovations. This model allows the linking of basic and applied research to the market, challenging the conventional, linear model of interaction. The TH model is based on: (a) the internal transformation in each one of the helices; (b) the influence of one helix upon another.

Universities provide advanced research and a ready supply of human capital in the form of skilled graduates; companies provide real-world problems, commercialization opportunities, and funding; and governmental organizations provide user feedback and regulatory support.

When business segments require high levels of specialization from multiple contributors [3], clusters arise.

The cluster concept - an aggregation of different players in a localized network [4] - has been defined in ambiguous ways, it is rather flexible, corresponding to a large variety of spatial and organizational concrete configurations. Trying to understand which of them, in terms of structure and partner characteristics, is most conductive to innovation is the general aim of the paper.

\section{RESEARCH PROBLEM}

The cluster we analyze involves an industrial player, an academic player and a public player belonging to the government sphere, which, in the life-science sector, typically are comprised of pharmaceutical firms, biotech firms, universities, research centers, and healthcare organizations such as hospitals, clinics, and healthcare institutions linked through an informal or formal arrangement.

We analyze what structural and nodal characteristics are best suited to maximize clusters' innovation, from an intracluster and an inter-cluster perspective.

The paper can make a theoretical contribution by enriching the literature on cluster dynamics and filling some gaps of the previous works: (a) the absence of significant contributions analyzing clusters of clusters and inter-cluster dynamics. Intercluster ties would be weak ties, and the strength of weak ties has been often advocated in the network literature; (b) the lack of clarity on the cluster concept: a chaotic concept (as argued in [5]). This raises many research questions; (c) the lack of agreement on the network structure most beneficial for innovation. We try to find an intermediate solution between sparse and dense structures, that are complementary, through the distinction between intra-cluster and inter-cluster dynamics and the combination of inter-firm resource pooling and cooperation; (d) the need of a contingent approach to evalutate dimensions affecting knowledge sharing besides network structure; (e) the scarce attention to the network's overall performance as a dependent, aggregated variable.

The paper's topic is relevant and grounded in reality because the cooperative options are widespread and the new systemic dimensions of technology and research, the interdisciplinary knowledge and the interdependence of productive processes led to cooperation and division of labor in $\mathrm{R} \& \mathrm{D}[6]$.

\section{CONCEPTUAL FRAMEWORK AND LITERATURE}

To examine the research problem, we will refer to literature on networks, and especially clusters, on the Triple Helix model for innovation. 
Studies examining the consequences of networks follow the structuralist perspective: an actor's payoff is a function of network structure and position. They found an impact of firm's network on its rate of innovation [7], often highlighting the benefits of networking. Scholars supported competing views: the benefits of strong vs weak ties and of disconnected [8] vs dense [9] structure. The question is whether network positions associated with the highest economic return lie between or within dense regions of relationships.

The concept of cluster could correspond to a large variety of spatial, institutional, and organizational concrete configurations, as proposed by reference [10]: an innovation cluster "comprises an ensemble of various organizations and institutions (a) that are defined by respective geographic localizations occurring at variable spatial scales, (b) that interact formally and/or informally through interorganizational and/or interpersonal regular or more occasional relationships and networks (c) that contribute collectively to the achievement of all kind of innovations within a given industry or domain of activity, i.e. within a domain defined by specific fields of knowledge, competences and technologies." It involves a wide range of variation and even starting from this definition, it is possible to build around the type of organizations involved, the best spatial scale for geographical localization, the focus on a single industry or domain, and the configuration of the network, as we do in the paper.

As for the impact of clusters on innovation, reference [11] showed that innovative research in biomedicine has its origins in regional clusters in the United States and in European nations. The success factors of a cluster have been identified with reference to the life-science industry as (a) crossfertilization and know-how sharing; (b) access to human capital; (c) availability of infrastructures; (d) cultural openness; (e) multidisciplinarity and spillovers among disciplines; (f) financial conditions supporting innovation [12].

Contrasting perspectives should be combined: learning and governance and knowledge exploration and exploitation [13], both needed for the innovation outcome.

A. Structural Characteristics: what structural characteristics of the cluster maximize the cluster's innovations, from an intra-cluster as well as an inter-cluster perspective.

\section{1) Size}

Size is the basic structural feature of networks [14], it determines the amount of knowledge circulating and spilling over between firms located in a cluster. In a Resource Dependence view, this can be an important predictor of firm performance, leading to reliance on a higher volume of flows of information and opportunities and a wider pool of product and process technologies during the innovation process.

As shown in reference [15], there is a positive relationship between the number of contacts of a node and a node's knowledge, if the innovative performance of each node increases, the overall cluster innovative performance will increase too.

Wider networks promote innovation indirectly by facilitating (a) increased specialization and division of labor which leads to more focused expertise development [16], (b) the scale effect (increases in inputs are rewarded with more than proportionate increases in output) that affects the transformation function $f$ of the innovation function, and (c) a leverage effect, given that each node in a cluster is part of other networks of different kinds.

Therefore, we can formulate the following proposition.

\section{P1: The larger the size of the life-science cluster, the} higher the cluster's innovative performance.

\section{2) Density/Structural Holes}

Despite the growing awareness that networks matter, the effects of specific elements of network structure on innovation remain ambiguous. This is the case of density (the number of the effective ties divided by the number of possible ties). There is a tension between two schools of thought about which network structure creates innovation: one supporting dense network structure [9], the other sustaining sparse network structure [8]. The absence of density results in the presence of many structural holes ${ }^{1}$.

A dense innovative cluster provides benefits both from the learning perspective (quick transmission of information, communication channels and pathways among actors, triangulation, intense interaction and integration, transfer of tacit, embedded knowledge, mutual understanding, coordinated action) [17] and from the governance perspective (lower transaction costs and barriers to resource mobilization, competitive practices, opportunism, risks; higher trust, reciprocity norms, shared identity). These conditions favour the exploitation component of innovation.

However in a dense cluster over time, the knowledge overlap between cluster organizations will increase [18], the only way to compensate for this trend is to increase the cluster firms' knowledge exchanges with outside entities. The presence of structural holes spanned between a cluster and other clusters determines the extent to which the cluster's knowledge base is continuously rejuvenated through knowledge inputs from outside the cluster [19].

In fact, brokerage - the presence of structural holes allows the detection and the development of new ideas from remote parts of the network synthesized across disconnected pools of information, diverse experiences, and novel combinations and re-combinations of ideas. These conditions favour the exploration component of innovation.

The question of how firms can better maintain the balance of exploration and exploitation remains unresolved [20]. Recent research has suggested the possibility of using organizations structure to meet this aim [21]. In different fields, from evolutionary biology to organization literature and network theory, we can find hints suggesting a configuration based on semi-isolated subgroups as a solution that may help strike the balance. In particular, we can combine the organizational learning arguments [22] with the small-world networks concept. The latter states that when a community of actors is structured into well-defined clusters that are only sparsely connected to each other, this structure can help to

\footnotetext{
${ }^{1}$ A structural hole exists between the brokered actors, two nodes in a network, if the nodes share a tie with ego but are not connected to each other
} [8]. 
create and preserve the requisite variety of knowledge in the broader community [20]; [23]; [24]. Usually, authors have focused on a single organization, suggesting that it can be broken into subgroups, semiautonomous subunits, we focus instead on inter-cluster dynamics, where the subgroups are the single clusters and the organization can be all the clusters considered together.

In the end, the bridging ties with other clusters allow for outside exploration, with the access to heterogeneous and novel ideas while the high density of clusters allows for effective exploitation of ideas and inside cluster exploration. In fact intra-cluster exploration is a "finalized exploration process", with a specific innovation outcome, that will shortly result in exploitation and is an exploration process that occurs in a "prearranged systemic way", a concept that is more similar to exploitation for certain characteristics. Therefore, inside the cluster, the dense structure seems to accomplish both exploration and exploitation aims. This is even more true in the life-science industry considering that the innovation process, is a complex sequence of stages, is a trial-and-error process, with a lot of feedback loops, where continuous shifts from exploration to exploitation as well as the opposite take place.

Therefore, networks that have both clustering and some amount of random linking between them, cluster-spanning bridges, seem the best solution to spur each cluster innovation: the benefits of local transmission and the information scope of cross-cluster connections can be simultaneously achieved.

Since we are focusing on the single cluster's innovation outcome and not on the innovation outcome of the network including all the clusters together, a concern may arise: crosscluster connections are able to engender an outflow of knowledge and a competition to appropriate the innovation outcomes. However, this seems to be not very relevant: at the exploration stage, the possibilities of exact imitation are reduced; the firm would have to know the exact way to implement the idea, which is difficult; the implementation process is very long and complex, and there would certainly be a first-mover problem.

The propositions provide a solution in which dense and sparse configurations co-exist at different scales and levels of the network, this can be defined as a multi-scaled cluster, where at the same time the logic of exploitation may prevail at some spatial scale but the logic of exploration may entail the commitment of some actors in open-ended networks [10].

The interaction of the two effects (density and spanning of structural holes) will have the greatest effect on innovation considering that, as stated by reference [25], closure can be a significant factor in realizing the value buried in a structural hole: catching new ideas from outside and effectively implementing them inside the cluster.

We can formulate the following propositions, distinguishing between intra-cluster and inter-cluster characteristics.

\section{a) Intra-cluster characteristic}

P2a): The higher the density in the life-science cluster, the higher the cluster's innovative performance.

b) Inter-cluster characteristic
P2b): The more the nodes in the life-science cluster span structural holes between the cluster and other clusters, the higher the cluster's innovative performance.

\section{c) Intra-cluster and inter-cluster characteristics}

P2c): The more the nodes in the life-science cluster span structural holes between the cluster and other clusters, the higher will be the positive impact of density in the life-science cluster on the cluster's innovative performance.

B. Nodes' Characteristics: what characteristics of nodes in a cluster maximize the cluster's innovations, from an intracluster and an inter-cluster perspective.

\section{1) Nodal vertical heterogeneity}

Vertical diversity means differences in alliance partners' operational contexts in the value chain, it implies the distinction among three categories: horizontal, upstream, or downstream [26]. In the specific case of the life-science cluster, the different players that occupy the different roles from downstream to upstream are: pharmaceutical company, biotech firm, university, research institute, institutions. Much of the existing literature on strategic alliances implicitly say that biotechnology firms act as value-added intermediaries between universities and downstream alliance partners. Their role is to facilitate transactions in a number of distinct ways. Here we consider for instance a biotech and a pharmaceutical firms as diverse and two pharmaceutical firms as equal. This kind of diversity seems to be a quite comprehensive measure, since in most cases it implies also resource-based diversity, industry-based diversity, technological diversity, and strategic fit.

Alliances between the different organizations could be horizontal (pharma-pharma, biotech-biotech), vertical downstream, vertical upstream. In this sense, we also distinguish between the effects of two forms of alliances: scale (two competitors come together to achieve scale economies) and link (two companies at different points in the value chain link up, thus obtaining synergies. Clearly, the risks of cooperation alliances will generally be greater in scale than in link alliances.

Referring to the learning and the governance theoretical perspectives, cognitive distance can represent both an opportunity (i.e., the novelty value of a relation), and a problem (i.e., mutual understanding or absorptive capacity that decreases with diversity, higher transaction costs, coordination difficulties, moral hazard risk) [14];[27]. In the end, we can make a distinction between knowledge development and knowledge transfer. Partner diversity probably favors the first one and disfavors the second one, because it increases the possible number of new recombinations, but adds difficulties to the transfer process. This resembles the exploration/exploitation trade-off: knowledge transfer is more related to exploitation and knowledge development to exploration.

Looking at the empirical works, we can assert that few studies reject the notion that there can be benefits associated with diversity but that these come with a cost; in any case, the findings are mixed. The main empirical findings are the following: reference [28] found that knowledge heterogeneity in the network was a significant predictor of the node's 
innovation performance; reference [29] maintained that innovation can only be achieved by collaborating with enterprises that have different knowledge bases; reference [30] did not find a positive impact of partner diversity on small and medium enterprises' survival.

Given the contrasting nature of the previous contributions, it is an interesting subject to investigate; we aim to analyze the effect of diversity in the intra-cluster and inter-cluster context ${ }^{2}$.

In the intra-cluster setting, with reference to the context drawn in proposition P2a, vertical diversity in the cluster has a positive moderation effect, strengthening the positive impact. This is because it will enhance the internal exploration process, favoring Schumpeterian "novel combinations," while the problem of the absorptive capacity will be counterbalanced by the presence of high connectivity in the cluster. Vertical diversity will also allow the effectiveness of the exploitation process that in the life-science industry requires the possession of complementary skills and experience, favoring a division of labor. Moreover, redundancy in a dense network is something that structurally discourages idea generation; this redundancy will be reduced in the presence of nodes' vertical diversity.

As for the specificities of the life-science industry, we can point out some important remarks. (a) First, partner diversity is really important to answer the regulatory requirements. The life-science $R \& D$ process is scheduled as a strict sequence of different stages that will be better performed if they involve different specialized players, covering different roles and responsibilities. Moreover, diversity will better allow feedback loops and support a trialand-error sequence, typical of life-science industry R\&D [31]. (b) Second, vertical diversity in this industry means also complementarity. Therefore, a cluster high in vertical diversity implies that firms may specialize in either exploitation or exploration, and seek the other in relations with other organizations with complementary specialization. Also, in the literature, arguments have been made that when firms combine complementary skills, greater innovation results [32]. If partners' vertical diversity implies complementarity, which in turn implies innovation, partners' vertical diversity drives innovation. (c) Third, partner diversity in the life-science industry involves a related knowledge background: players act in subsequent phases of the same macro-process, and thus it is possible to suppose that they own the same background in terms of basic skills, shared language, and knowledge of the most recent scientific or technological developments; technoorganizational systems (TOS), molecules, and drugs [33]. This reduces the concern of absence of absorptive capacity.

In the Inter-cluster setting, with reference to proposition $\mathbf{P 2 b}$, there is a node of the cluster that is spanning a structural hole between the cluster and other clusters. The link connecting cluster to cluster should be a weak tie, in a sparse

\footnotetext{
${ }^{2}$ In the proposition formulation, by the level of vertical diversity in the intra-cluster setting (therefore diversity at the network level), we mean the range of diverse partners inside the cluster. The meaning will be slightly different for the inter-cluster setting, where the diversity is measured for pairs of nodes (the two nodes that are at the end of the structural hole) and not in a network.
}

configuration, and the problem of absorptive capacity is higher than in the intra-cluster case because the two extreme nodes are gatekeepers. If learning performance from interaction is the mathematical product of novelty value and understandability, the result is an inverted- $U$ shape relation with cognitive distance. Optimal cognitive distance lies at the maximum of the curve [14].

The low level of vertical diversity implies redundancy in resources [8] and knowledge, turning core capabilities in core rigidities (the addition of similar capabilities does not increase innovation, since possible new combinations of existing capabilities quickly become exhausted). It may involve interfirm rivalry, as the partners may compete in the same industry. This implies that the partners may not be willing to transfer knowledge and also there will be a higher risk for negative spillovers.

With a high level of vertical diversity exposure to diverse industries and technologies may provide firms with valuable learning opportunities [34]. However, beyond a point there will be decreasing returns to learning [13]. Too-high diversity may suggest that firms will have too little in common to offer each other cooperative benefits; the collaborative opportunities may be difficult to pursue, because the partners will experience high costs of sharing and transferring knowledge [35];[36] and low absorptive capacity.

Based on the previous framework, we can desume that a moderate level of partner diversity (e.g., between biotech and pharmaceutical firms) is ideal: it contributes more to firm innovation than does a very low or very high level of diversity, partners have a sustainable level of transaction costs and competition and a good level of complementarity and absorptive capacity. Partner capabilities are diverse, creating a large number of possible combinations, but not so diverse so as to prevent efficient assimilation.

We can formulate the following propositions.

\section{a) Intra-cluster characteristic}

P3a): The partners' vertical diversity in the life-science cluster positively moderates the impact of size and density on the cluster's innovative performance.

The higher the level of partners' vertical diversity in the cluster, the higher the positive impact of size and density on the cluster's innovative performance.

\section{b) Inter-cluster characteristic}

P3b): The vertical diversity between the two nodes spanning an inter-cluster structural hole moderates the impact of the inter-cluster structural hole on the cluster's innovative performance with an inverted $U$-shaped pattern.

A too-low level and a too-high level of vertical diversity between the two nodes spanning the inter-cluster structural hole reduce the positive impact of the inter-cluster structural hole on the cluster's innovative performance.

A moderate level of vertical diversity between the two nodes spanning the inter-cluster structural hole enhances the positive impact of the inter-cluster structural hole on the cluster's innovative performance. 


\section{2) Geographical distance}

We investigate whether geography matters and determine the impact of nodes' geographical distance in favoring a cluster's innovation process. We are trying to apply what in the firm context would be the definitions of the optimal boundaries of a firm, in the cluster context. The question is motivated by the consideration that there are some elements or theories that support localization and proximity for innovation and others that are in favor of a wider geographical extension, all related to the learning or governance approach.

Factors supporting geographical proximity are: (a) transaction costs reduction and development of relational dimensions; (b) location-specific drug development for epidemiological reasons; (c) location-specific regulatory framework; (d) tacit knowledge transfer, frequency of interaction, trust; (e) location-specific assets (agglomeration economies, pool of skilled labor; scientific, technical, commercial spillovers) in positive "externality arenas" [31]; (f) the theory of proximity in the network theory that identifies proximity as the main facilitator of knowledge flow [37].

Factors supporting geographical distance are: (a) need of an escape from local embedding for innovation (cognitive distance) [38]; (b) embedding in virtual communities, with internet use reducing transaction costs; (c) substitutive role of frequent meetings; (d) avoidance of lock-in effect (social legitimacy; location-specific investments; institutional embedding: local obligations of conformity); ( $g$ ) tension toward trans-local, disembedded clusters, in the real world and in the institutional recommendations (e.g. European Commission) to enhance competitiveness; (h) arbitrage opportunities with respect to regulatory framework in case of trans-local collaboration.

Moreover, during the last decade, there seems to be a widespread perception that if success is to be attained, the THM (Triple Helix Model) is the ideal referential, encompassing the territorial scale. Although localized in a specific space, the activities carried out in a territory, not necessarily originate from that space or have their effects just inside that area.

Therefore, a better solution for innovation would be a balance between local and non-local players inside the cluster, as well as in the inter-cluster connections: the shared context of a local circuit and of remote cooperation will be complementary resources [4], favouring the combination of exploration and exploitation. A moderate level of geographical distance will enhance the positive impact of size, density, and structural holes on a cluster's innovative performance, as stated in the following two propositions.

\section{a) Intra-cluster characteristic}

P5a): The geographical distance between the nodes in the life-science cluster moderates the impact of size and density on the cluster's innovative performance with an inverted $U$-shaped pattern.

A too-low level and a too-high level of geographic distance between the nodes in the life-science cluster reduce the positive impact of size and density on the cluster's innovative performance.
A moderate level of geographic distance between the nodes in the life-science cluster enhances the positive impact of size and density on the cluster's innovative performance

\section{b) Inter-cluster characteristic}

P5b): The geographical distance between the two nodes spanning an inter-cluster structural hole moderates the impact of the inter-cluster structural hole on the cluster's innovative performance with an inverted $U$-shaped pattern.

A too-low level and a too-high level of geographic distance between two nodes spanning an inter-cluster structural hole reduce the positive impact of the inter-cluster structural hole on the cluster's innovative performance

A moderate level of geographic distance between two nodes spanning an inter-cluster structural hole enhances the positive impact of the inter-cluster structural hole on the cluster's innovative performance.

\section{DISCUSSION AND CONCLUSIONS}

Clusters have become a prevalent form of industrial organization and their innovativeness is considered to be a key source of regional and national competitive advantage.

The primary contribution of the study is a framework that suggests an understanding of the factors that give rise to differential innovative outcomes across different clusters. Other contributions have been explained in the research problem section.

We want to underline the scope conditions of our predictions. The propositions are valid for a specific context that is a highly regulated setting, such as the life science industry, having some specificities: a process involving different, strict stages that must follow definite rules, as in clinical trials, and to which the contribution of diverse players healthcare organizations or governmental organizations such as the technical and scientific public bodies of the National Health Service - are fundamental.

This paper could be the basis for an original empirical quantitative study, enriching research on cluster-based innovation by using Social Network Analysis (SNA) methods. In fact the use of constructs and concepts derived from social network analysis in the clusters' actual operationalization is only occasional [19]. It would be possible to test the THM (Triple Helix Model) with empirical evidence coming from fieldwork, adopting statistical and quantitative methods.

The conclusions of the work could be significant for the world of the practice in that they could drive the choice of the best structural configuration and the best partner mix, thus increasing the managerial capabilities with reference to clusters' formation.

\section{REFERENCES}

[1] H. Etzkowitz and L. Leydesdorff, "The endless transition: A Triple helix of university-industry-government relations, Introduction to a theme issue", Minerva, vol. 36, pp. 203-208, 1998.

[2] H. Etzkowitz and L. Leydesdorff, "The dynamics of innovation: from national systems and Mode 2 to a Triple helix of university-industrygovernment relations", Research Policy, vol. 29, pp. 109-123, 2000. 
[3] F. Ghadar, J. Sviokla, and D. A. Stephan, "Why life science needs its own silicon valley", Harvard Business Review, 2012.

[4] A. Q. Curzio and M. Fortis, Complexity and industrial clusters. Dynamics and models in theory and practice. New-York: PhysicaVerlag, 2003.

[5] R. Martin and P. Sunley, "Deconstructing clusters: chaotic concept or policy panacea?", Journal of Economic Geography, vol. 3 (1), pp. 5-35, 2003.

[6] B. Goransson and C. M. Palsson, Biotechnology and innovation systems: The role of public policy. New York: Edward Elgar Publishing, 2011.

[7] G. Ahuja, "Collaboration networks, structural holes, and innovation: a longitudinal study", Administrative Science Quarterly, vol. 45, pp. 425$455,2000$.

[8] R. S. Burt, Structural holes: the social structure of competition. Cambridge, MA: Harvard University Press, 1992.

[9] J. S. Coleman, "Social capital in the creation of human capital", American Journal of Sociology, vol. 94, pp. 95-120, 1988.

[10] A. Hamdouch, "Innovation clusters and networks: A critical review of the recent literature", 19th EAEPE conference, Universidade do Porto, 1-3 November 2007.

[11] J. Owen-Smith, M. Riccaboni, F. Pammolli, and W. W. Powell, "A comparison of US and European university-industry relations in the life sciences", Management Science, vol. 48 (1), pp. 24-43, 2002.

[12] F. Gianfrate, Economia del settore farmaceutico. Bologna: Il Mulino, 2004.

[13] J. March, "Exploration and exploitation in organizational lerning", Organization Science, vol. 2 (1), pp. 101-123, 1991.

[14] B. Nooteboom, Inter-firm collaboration, learning and networks - An integrated approach. Routledge, 2004.

[15] K. Nobeoka, J. H. Dyer, and A. Madhok, "The influence of customer scope on supplier learning and performance in the Japanese automobile industry", Journal of International Business Studies, vol. 33 (4), pp. 717 736, 2002.

[16] A. L. Saxenian, "The origins and dynamics of production networks in the Silicon Valley", Research policy, vol. 20 (5), pp. 423-437, 1991.

[17] U. Zander and B. Kogut, "Knowledge and the speed of the transfer and imitation of organizational capabilities: an empirical test", Organization Science, vol. 6 (1), pp. 76-92, 1995.

[18] R. Pouder and C. H. St. John, "Hot spots and blind spots: geographical clusters of firms and innovation", The Academy of Management Review, vol. 21 (4), pp. 1192-1225, 1996.

[19] R. Dandi, A. Sammarra, C. Muzzi, and L. Biggiero, "The identification of innovation catalysts in the Triple helix: empirical evidence in the aerospace industrial cluster in central Italy", XVIth ISA World Congress of Sociology, Durban (South Africa), 23-29 July 2006.

[20] C. Fang, J. Lee, and M. A. Schilling, "Balancing exploration and exploitation through structural design: the isolation of subgroups and organizational learning", Organization Science, vol. 21 (3), pp. 625-642, 2010.

[21] M. Jacobides, "The inherent limits of organizational structure and the unfulfilled role of hierarchy: lessons from a near-war", Organization Science, vol. 18 (3), pp. 455-477, 2007.

[22] J. G. March, "Parochialism in the evolution of a research community: the case of organization studies", Management and Organization Review, vol. 1 (1), pp. 5-22, 2004.

[23] B. Uzzi and J. Spiro, "Collaboration and creativity: the small world problem", American Journal of Sociology, vol. 111 (2), pp. 447-504, 2005.

[24] S. Yayavaram and G. Ahuja, "Decomposability in knowledge structures and its impact on the usefulness of inventions and knowledge-base malleability", Administrative Science Quarterly, vol. 53(2), pp. 333-362, 2008.

[25] R. S. Burt, "The network structure of social capital" in Research in Organizational Behavior, B. M. Staw and R. I. Sutton, Eds. Elsevier Science JAI, 2000, pp. 345-423.
[26] O. P. Bruyaka, "Alliance partner diversity and biotech firms' exit: differing effects on dissolution vs. divestment", Cologne Conference, Managing Alliance Relationships, Session 1104, 2008.

[27] A. Goerzen and P. W. Beamish, "The effect of alliance network diversity on multinational enterprise performance", Strategic Management Journal, vol. 26 (4), pp. 333-354, 2005.

[28] S. Rodan and D. C. Galunic, "More than network structure: how knowledge heterogeneity influences managerial performance and innovativeness", Strategic Management Journal, vol. 25, pp. 541-562, 2004.

[29] M. J. Nieto and L. Santamaria, "The importance of diverse collaborative networks for the novelty of product innovation", Technovation, vol. 27, pp. 367-377, 2007.

[30] Watson, J. (2007). Modeling the relationship between networking and firm performance. Journal of Business Venturing, 22 (6): 852-874.

[31] G. Maier and S. Sedlacek, Spillovers and innovations: space, environment and the economy. Vienna: Springer Wien New-York, 2006.

[32] K. W. Glaister, "UK-Western European strategic alliances: motives and selection criteria", Journal of Euro-Marketing, vol. 5 (4), pp. 5-35, 1996.

[33] M. Ohba and P. N. Figueiredo, "Innovative capabilities and strategic alliances: who is gaining what in the pharmaceutical industry?", Journal of commercial biotechnology, vol. 13 (4), pp. 273-282, 2007.

[34] D. Teece, G. Pisano, and A. Shuen, "Dynamic capabilities and strategic management", in Resources, Firms and Strategies, N. Foss, Ed. Oxford: Oxford University Press, 1997, pp. 268-288.

[35] B. Kogut and U. Zander, "Knowledge of the firm, combinative capabilities, and the replication of knowledge", Organization Science, vol. 3, pp. 383-397, 1992.

[36] P. J. Lane and M. H. Lubatkin, "Relative absorptive capacity and interorganizational learning", Strategic Management Journal, vol. 19, pp. 461-477, 1998.

[37] L. Giustiniano and F. Bolici, "Organizational trust in a networked world: analysis of the interplay between social factors and Information and Communication Technology", Journal of Information, Communication, Ethics in Society, vol. 10(3), pp. 187-202, 2012.

[38] P. Oinas and E. J. Malecki, "The evolution of technologies in time and space: from national to regional to spatial innovation systems", International Regional Science Review, vol. 25 (1), pp. 102-131, 2002. 